\title{
Research on Education Management in the Age of Big Data
}

\author{
Shasha Cheng \\ College of Business Administration, Fujian Jiangxia University, Fuzhou, Fujian, 350108, China
}

Keywords: Big data, Education management, Effectiveness.

\begin{abstract}
The arrival of the era of big data has significantly changed the traditional way of education management, which can be called a new revolution in the education management industry. The analysis of big data in the field of education management shows that big data is the collection of various kinds of data in the education system, with practicability, diversity and other characteristics, and it can comprehensively analyze and judge a variety of complex data in kinds of schools at the fastest speed. By applying big data to education management, the efficiency of education management can be effectively improved in educational institutions. This paper analyzes the main contents of education management in the age of big data, elaborates the related influence of big data era on education management, discusses the urgency of implementing education management revolution in the age of big data, and puts forward some ideas for improving the effectiveness of education management in the age of big data.
\end{abstract}

\section{Introduction}

Big data can be said to be formed on the basis of the continuous development of data in the traditional sense. Different from traditional data, big data mainly uses modern information technology and computers to carry out all-round collection of various types of data, and manage and integrate the collected data with modern information technology. In the implementation of education management, educational institutions will generate a large amount of data, which can reflect many conditions of school education and teaching management and is rather valuable for school education management. Based on the era of big data, the educational management methods of educational institutions can effectively shorten the time of collecting information and expand the scope of data utilization by scientifically applying various types of big data, so as to provide practical and feasible reference for education management.

\section{The Main Content of Education Management in the Age of Big Data}

Big data has been born in view of the continuous development of modern information technology. The application of big data to a variety of industries can demonstrate the value of these industries. The work of applying big data to education management mainly includes the following five aspects: The first is the basic information of the individual educator and the learner, which mainly covers learning records, household registration information and health status. The above data are closely related to individuals and are important information to learn about individuals. In the education management work, the individual information of the learner can be divided into two parts. One part is the personal information of school staff, the other part is the personal information of the learner. The second is the overall educational information of the educational institution, involving quite a lot of content. Besides educational information, it also covers schools' campus security, construction, facilities and equipment and other relevant data. The third is the basic information of education, mainly about education and teaching information, covering teaching assessment, classroom education and teaching information and teacher information, etc. Educational institutions can scientifically collect the above data and information, so that they can understand the actual education and teaching situation of schools anytime and anywhere. The fourth is regional education information 
mainly covering off-campus information, which includes information on teaching and research in the school area and various types of educational information related to schools. The information can not only strengthen the connection between schools and the education authorities, but also promote the sharing of various data and information of schools, so as to greatly promote the steady development of schools' education and teaching work. The fifth is the overall education information, a comprehensive understanding of the education and teaching status of each region, mainly based on the collection of all the information of schools, in order to improve the effectiveness of education management.

\section{The Related Influence of the Age of Big Data on Education Management}

Firstly, the possibility of implementing personalized education management for educational institutions has been increased. The full use of network technology brings great possibilities for modern people's life, study and work. Especially, the large number of applications of WeChat, QQ and Weibo has greatly enriched the life of modern people, thus to bring rich data to people. Based on the big data background, the dynamic data information of modern people can be recommended to the data user through personalized collection, classification and aggregation. At a time when big data continues to expand, educational institutions can naturally apply the relevant functions of big data. According to the different characteristics of the students and the teaching content, teachers can scientifically apply big data to design differentiated educational teaching programs for students to achieve personalized education management methods. In the context of big data, educational institutions can dynamically capture the information of individual learners, so as to fully exert the effects of big data prediction and tracking. The use and establishment of personal information files for students allow schools to find a personalized learner file management method to improve the accuracy of education management. At the same time, it is also possible to use a personalized file management model to drive teachers and students to more fully grasp relevant theories and skills, providing strong guarantee for autonomous learning, which increases the possibility of implementing personalized education management in schools.

Secondly, the educational resources of various schools have been further expand. With the continuous development of the education industry, the teaching conditions and facilities of schools have been greatly improved, thus providing better material conditions for school education. Due to the continuous development of modern information technology, it has brought greater development and new opportunities for the continued development of China's education. The age of big data has promoted school education management to achieve great improvement. In particular, the online education and long-distance network education have been well popularized, which have established a broader development platform for the expansion of school education and of course have added a large amount of teaching resources to the deepening of China's education reform. Learners can use web technology to find the appropriate teaching resources in order to broaden their knowledge. Based on the background of big data, teachers can use network technology to collect more abundant classroom teaching resources, and apply them to classroom teaching, so as to reasonably expand the resources of teaching materials so that students can learn more comprehensive content, thus to promote the quality of classroom education and teaching.

\section{The Urgency of Implementing the Education Management Revolution in the Age of Big Data}

The first is the urgent need to cultivate high-quality talents. For a long time, the development of education in China has always been a hot topic of concern to all parties. The key to education management is to educate people, i.e., to cultivate excellent high-quality talents that are more in line with the development needs of the times, which is the subject every school needs to study carefully. Under the general trend of the development of world economic integration, the Chinese economy has also developed rapidly, which has promoted the further improvement of China's comprehensive strength. Under this circumstance, China needs more high-quality compound talents, and the demand 
for high-quality talents in various industries will only increase and will not decrease. Therefore, each school should also keep pace with the development of the times and make full use of the information management mechanism to promote the development of education management. It is necessary to transform traditional concepts and truly keep education management up to the current development pace.

The second is the urgent requirement of education institution sustainable development. Big data contains abundant or even huge information itself, all of which can help teachers and students to get the materials they need, so that their work can be carried out smoothly. At the same time, big data also has the function of efficient disposal of information, which can better realize information sorting, statistics, analysis and other related work, thus bringing great convenience to relevant personnel. Schools can apply big data to students' individual information, so that teachers can introduce more suitable teaching measures for students' own development to promote the long-term development of students.

The third is the urgent need to promote social progress. The main purpose of schools' implementation of teaching management is to enable students and the society to achieve mutual connection, so as to cultivate innovative talents for social development. However, the demands placed on talent by society in the age of big data are also constantly changing. Therefore, school education and teaching work should also continue to be innovated in order to catch up with the pace of social development. By implementing education management under big data, talents can be better adapted to the current society, so as to promote the sustainable development of society.

\section{Some Ideas for Improving the Effectiveness of Education Management in the Age of Big Data}

\subsection{Improving the management system}

The education management work in the age of big data should adapt to the changes of the current era, apply big data to update schools' education management system, thereby improving the actual effectiveness of education management, and pushing the school education management to a higher level. First, there have been new changes in the methods of education management. In the previous education management system, because the data information involved a quite narrow range and had relatively simple content, most of schools did not pay attention to the important value of data, resulting in a simple data system that cannot effectively meet the needs of education management in the age of big data. In view of this, in the age of big data, schools must continue to innovate, change and update the previous education management system, and focus on improving the analysis and storage of the education management system, in order to provide favorable conditions for big data applications and education management. Second, the age of big data has transformed the inherent working methods of education management, paying more attention to whether education administrators are in place for the education management of schools. The age of big data requires that school education management should conduct a comparative analysis of current data and previously mastered data, so as to find relevant problems in the least amount of time and actively deal with them with relevant measures, to minimize the risk of education management. Third, the age of big data has promoted the innovation of education management, thereby enhancing the creative responsibility of educators. Therefore, it is necessary to adapt to the new background of the age of big data, actively update the existing education management system, and enhance the sense of responsibility and mission of education managers to achieve the purpose of effective implementation of education management.

\subsection{Implementing a personalized education management model}

School education management involves a wide range of issues. Any kind of information resources has extremely important value for education management and is indispensable data in education management. In the age of big data, the relevant data that education management provides can not 
only conduct a comprehensive analysis of the needs of students, but also design a personalized education management plan according to the specific characteristics of students, in order to achieve personalized teaching effects. In the process of curriculum design, educational institutions must fully consider the goal of individualized education, and change the teaching methods in the traditional sense according to the needs and individualized characteristics of students, in order to better meet the educational management requirements of the age of big data. Based on the background of big data, it is necessary to break the traditional constraints and implement the concept of open school in the education management, to continuously improve the learning ability of learners and improve the effectiveness of education management. Schools should fully integrate the content of teaching, apply modern information technology to develop courseware, and pass it to the teaching platform for students to carry out micro-class learning with the network to further enhance students' independent learning ability. Therefore, school education management in the age of big data should fully apply big data to expand teaching resources and enhance learners' independent learning ability, and use individualized education methods to enhance education management capabilities.

\subsection{Improving big data application capabilities}

Big data can be said to be an important factor in promoting education management. According to the requirements of education management in the age of big data, it can be found that in the process of implementing education and teaching, education management workers must regard students as the main body and continuously improve their activity and participation in the classroom. Because big data itself has a very large storage space and a relatively high information processing capacity, schools can use big data to create their own network management platform, comprehensively store and manage the personal information of all students, and carry out according to the information. The application of data will lead to the introduction of teaching measures that meet the actual requirements, so that students can develop in all directions. However, in reality, many schools have not paid enough attention to the application of big data, and have not linked big data to education management, so that school education management is generally lacking in effectiveness. Therefore, we must have a specific understanding of the use of big data in education management, and then find out the existing problems, solve them in a targeted manner, and effectively improve the ability to apply big data, thereby improving the effectiveness of education management workers. First, the school should fully affirm the application value of big data, and clearly discuss the prominent role of big data in education management, so that school educators can have a clearer understanding of big data and create a great environment for big data applications. Second, schools should guide the education management personnel to master the application process, purpose and standards of big data, and avoid blindly applying big data. Third, schools should also formulate a big data application policy in line with the actual situation of schools, further improve schools' education management facilities and equipment, and guide education management workers to use the big data service to schools' education management work in an effort to promote the education management work to achieve greater results.

\section{Summary}

In general, there is a difference between big data and traditional data. Big data applies modern information technology to implement all-round collection of various types of data, and applies information technology to manage and integrate the collected data. Therefore, in the age of big data, the educational management of educational institutions can fully apply big data to compress the time of collecting various types of information, expand the scope of schools' application data, and provide the reference data needed for the education management work, to improve the effectiveness of school education management. 


\section{References}

[1] Zhang Gang. Analysis of the Opportunities and Challenges of Deepening Development of Continuing Education in the Age of Big Data, Contemporary Continuing Education, 2015 (4).

[2] Zhang Yuan. Research on the Reform of Higher Education Mode of Thinking in Combination with the Development of Big Data Era, Journal of Pu'er University, 2015(6).

[3] Yuan Hui. Application of Big Data Technology in College Student Education Management, Journal of Shanxi Energy College, 2017(4).

[4] Zhong Ping. Innovation of College Student Education Management Mode under the Background of Big Data_Based on the Yanyuan Online Network Integrated Service Platform of Yanshan University, Education Theories, 2016(7).

[5] Yang Ge, Wang Haolang, Chen Huaan. Analysis of Data Processing Analysis Tools in University Continuing Education Management under the Background of Big Data, Education Modernization, 2016(9). 